\title{
Ocorrência de plantas daninhas em cultivo consorciado de café e nogueira-macadâmia ${ }^{1}$
}

\author{
Vinícius de Castro Silva ${ }^{2}$, Marcos José Perdoná ${ }^{3}$, Rogério Peres Soratto ${ }^{2}$, Eduardo Negrisoli ${ }^{4}$
}

\section{ABSTRACT}

Occurrence of weeds in coffee

intercropped with macadamia

Arborization can benefit coffee plantations by reducing the wind speed and temperature variation in the crop. It is also possible that the incident radiation can affect the weed populations and reduce the need for their control. This study aimed at assessing the weeds population and distribution, in arabica coffee intercropped with three macadamia cultivars, six years after planting, in Dois Córregos, São Paulo State, Brazil. Treatments consisted of a $3 \times 3+1$ factorial scheme, i.e., coffee intercropped with three macadamia cultivars (HAES 816, IAC 4-20 and IAC 9-20) and three sampling positions of weeds in the intercropping (in the macadamia tree canopy projection, among the macadamia tree canopies projections and in the single rows), plus an additional treatment (sole coffee). The weeds incidence and control, as well as their phytosociological characterization, were evaluated. For coffee intercropped with macadamia, the weeds occurrence and number of species were smaller than for sole coffee. For the projection in the canopy and among canopies of macadamia trees, there was an average decrease of $82 \%$ in the occurrence of weeds, in comparison with the sole coffee. The IAC 9-20 cultivar was more efficient in reducing the occurrence of weeds, when intercropped with coffee, for presenting a taller canopy, with a larger diameter.

KEY-WORDS: Coffea arabica L.; Macadamia integrifolia Maiden \& Betche; invasive plant; shading.

\section{INTRODUÇÃO}

Apesar de, originalmente, ser uma planta de sub-bosque, o cafeeiro foi melhorado por décadas, resultando em plantas mais produtivas a pleno sol (café solteiro) e, por isto, esta é a principal modalidade de cultivo no Brasil (DaMatta et al. 2007). Porém, a variabilidade climática é o principal fator responsável

\section{RESUMO}

A arborização pode beneficiar os cafezais, reduzindo a velocidade dos ventos e a amplitude térmica na cultura. É possível, ainda, que a diminuição na radiação incidente possa influenciar a população de plantas daninhas e diminuir a necessidade de seu controle. Objetivou-se, com este trabalho, avaliar a população e a distribuição de plantas daninhas, na cultura de café arábica consorciado com três cultivares de nogueira-macadâmia, seis anos após o plantio, em Dois Córregos (SP). Os tratamentos consistiram de esquema fatorial $3 \times 3+1$, ou seja, café consorciado com três cultivares de nogueiramacadâmia (HAES 816, IAC 4-20 e IAC 9-20) e três locais de amostragem das plantas daninhas no consórcio (na projeção da copa da nogueira-macadâmia, entre as projeções das copas da nogueira-macadâmia e na entrelinha solteira), além de um tratamento adicional (café solteiro). Foram avaliados a incidência e o controle de plantas daninhas, bem como a caracterização fitossociológica. No cultivo de café consorciado com nogueiramacadâmia, a ocorrência e o número de espécies de plantas daninhas foram menores que no cultivo de café solteiro. $\mathrm{Na}$ projeção da copa e entre as projeções das copas da nogueiramacadâmia, houve, em média, $82 \%$ de redução na ocorrência de plantas daninhas, em comparação ao café solteiro. A cultivar IAC 9-20, por apresentar copa mais alta e de maior diâmetro, foi mais eficiente na redução da ocorrência de plantas daninhas, no consórcio com café.

PALAVRAS-CHAVE: Coffea arabica L.; Macadamia integrifolia Maiden \& Betche; planta invasora; sombreamento.

pelas oscilações e frustrações na produção de café, no Brasil, e alterações climáticas, como o aquecimento global, causam diminuições na sua produção, sendo necessário o uso de medidas mitigadoras, como a arborização (Camargo 2010).

A arborização, além de minimizar a exposição do cafeeiro a riscos climáticos, pode proporcionar a agregação de uma fonte de renda extra aos cafeiculto-

1. Trabalho recebido em maio/2013 e aceito para publicação em dez./2013 (nº registro: PAT 24021).

2. Universidade Estadual Paulista (Unesp), Faculdade de Ciências Agronômicas, Departamento de Produção e Melhoramento

Vegetal, Botucatu, SP, Brasil.E-mails: vi_agronomia@hotmail.com, soratto@fca.unesp.br.

3. Agência Paulista de Tecnologia dos Agronegócios (APTA), Regional Centro-Oeste, Bauru, SP, Brasil.

E-mail: marcos.perdona@yahoo.com.br.

4. Techfield Consultoria Agrícola, Botucatu, SP, Brasil.E-mail: eduardo.negrisoli@gmail.com. 
res e melhor aproveitamento da mão de obra, durante o ano, beneficiando, sobremaneira, a agricultura familiar (Pezzopane et al. 2010).

No Brasil, o cultivo do café arborizado com árvores de nogueira-macadâmia (Macadamia integrifolia Maiden \& Betche) ocorre desde a década de 1970 (Perdoná et al. 2012). Pezzopane et al. (2010) verificaram redução de $72 \%$ na velocidade do vento e de $2,2^{\circ} \mathrm{C}$ na média da temperatura máxima do ar, no cultivo de café arborizado com nogueira-macadâmia. Desta forma, o sombreamento moderado pode contribuir para a manutenção da sustentabilidade da produção da cultura do café (Pezzopane et al. 2007).

$\mathrm{O}$ cafeeiro é uma planta muito sensível à mato-competição, requerendo um sistema de manejo de plantas daninhas eficiente (Alcântara \& Ferreira 2009). A presença de outras espécies, mesmo que daninhas, nas entrelinhas, pode trazer benefícios para a cultura do café, como o aumento da diversidade biológica e da proteção da superfície do solo contra a erosão (Fialho et al. 2010), porém, a competição de plantas daninhas por nutrientes é um forte fator limitante ao crescimento das plantas de café, reduzindo, em até $50 \%$, o teor de macronutrientes e, em até $41 \%$, o desenvolvimento de cafeeiros jovens (Carvalho et al. 2013). Alcântara \& Ferreira (2009) observaram $20 \%$ de perdas na produtividade de lavouras adultas.

Segundo Pezzopane et al. (2010), em cultivos de café conilon (Coffea canephora Pierre) arborizados com macadâmia, a transmissividade da radiação fotossinteticamente ativa sofreu variações entre 17\% e $89 \%$, em relação ao café solteiro. Sombreamentos de $40 \%$ e $86 \%$ diminuíram, respectivamente em $74 \%$ e $99 \%$, a massa seca de plantas daninhas, nas entrelinhas de lavouras de café (Coelho et al. 2004). O número, a diversidade e a relação de importância entre as espécies também variam conforme o sistema de cultivo (Ferreira et al. 2011). A arborização com grevíleas reduziu a densidade e a frequência relativa e elevou a diversidade de espécies de plantas daninhas (Silva et al. 2006).

Cultivares de macadâmia apresentam diferentes arquiteturas de copa (Perdoná et al. 2012), o que interfere no sombreamento. Em sistemas agroflorestais, as espécies utilizadas e os arranjos entre as culturas interferem na frequência, densidade e biomassa das plantas daninhas, podendo diminuir a competição destas com a cultura do café (Schulz et al. 1994).

O controle de plantas daninhas é uma das práticas mais intensivas, na condução de lavouras cafeeiras, representando, aproximadamente, $9 \%$ do custo de produção da cultura, na fase produtiva (Pais et al. 2011, Agrianual 2012). O uso de métodos mecânicos promove a compactação do solo (Pais et al. 2011) e a aplicação de herbicidas provoca alterações negativas nos atributos físicos, químicos (Alcântara et al. 2009, Araújo-Júnior et al. 2011, Pais et al. 2011) e na microbiota do solo (Alcântara \& Ferreira 2009).

Diante desses fatos, a menor necessidade de controle de plantas daninhas pode ser um fator benéfico ao cafezal, podendo diminuir o custo de produção e melhorar as condições da lavoura. Contudo, não existem, na literatura, informações sobre o desenvolvimento e distribuição de plantas daninhas, no cultivo consorciado de cultivares de nogueira-macadâmia com o cafeeiro. Assim, objetivou-se avaliar a ocorrência de plantas daninhas na cultura de café arábica (Coffea arabica L.) consorciada com três cultivares de nogueira-macadâmia, após seis anos do plantio.

\section{MATERIAL E MÉTODOS}

O estudo foi realizado no município de Dois Córregos, SP (22 $21^{\circ} \mathrm{S}, 48^{\circ} 22^{\prime} \mathrm{W}$ e $753 \mathrm{~m}$ de altitude). Segundo a classificação de Köppen, o clima da região é tropical, com estação seca no inverno, temperatura média anual de $21,2^{\circ} \mathrm{C}$ e regime pluviométrico anual em torno de $1.342 \mathrm{~mm}$ (Cepagri 2012).

O solo do local é um Latossolo Vermelho-Amarelo distrófico (Santos et al. 2006) e os resultados das análises químicas, na camada de 0-0,20 m de profundidade, antes da instalação do experimento, foram: $\mathrm{pH}\left(\mathrm{CaCl}_{2}\right)=5,2 ; \mathrm{P}($ resina $)=5 \mathrm{mg} \mathrm{dm}^{-3} ; \mathrm{M} . \mathrm{O} .=$ $17 \mathrm{~g} \mathrm{dm}^{-3} ; \mathrm{K}=0,8 \mathrm{mmol}_{\mathrm{c}} \mathrm{dm}^{-3} ; \mathrm{Ca}=9,0 \mathrm{mmol}_{\mathrm{c}} \mathrm{dm}^{-3}$; $\mathrm{Mg}=7 \mathrm{mmol}_{\mathrm{c}} \mathrm{dm}^{-3} ; \mathrm{Al}=1 \mathrm{mmol}_{\mathrm{c}} \mathrm{dm}^{-3} ; \mathrm{H}+\mathrm{Al}=$ $18 \mathrm{mmol}_{\mathrm{c}} \mathrm{dm}^{-3}$; saturação por bases $=49 \%$. Os resultados da análise granulométrica foram: argila $=$ $103 \mathrm{~g} \mathrm{~kg}^{-1}$, silte $=71 \mathrm{~g} \mathrm{~kg}^{-1}$ e areia $=826 \mathrm{~g} \mathrm{~kg}^{-1}$. A correção do solo seguiu as indicações para a cultura do cafeeiro no Estado de São Paulo (Raij et al. 1996).

Em fevereiro de 2006, foi instalada a irrigação por gotejamento, composta por gotejadores autocompensantes, espaçados $0,7 \mathrm{~m}$ entre si e com vazão de $1,0 \mathrm{~L} \mathrm{~h}^{-1}$ de cada. O manejo da irrigação foi realizado utilizando-se sensores de tensão de água de $25 \mathrm{kPa}$ (sistema IRRIGÁS), instalados às profundidades de $20 \mathrm{~cm}$ e $60 \mathrm{~cm}$, mantendo-se sempre úmido o sensor instalado a $20 \mathrm{~cm}$. Neste mesmo período, foram plantadas, em consórcio com a cultivar Obatã (IAC 1669-20) (C. arabica L.), três cultivares de nogueira- 
-macadâmia (HAES 816, originária do Hawaii Agricultural Experiment Station, e IAC 4-20 e IAC 9-20, originárias do Instituto Agronômico de Campinas, enxertadas sobre porta-enxerto Aloha (IAC 10-14), com características de copa contrastantes) (Tabela 1).

As mudas de café foram plantadas em espaçamento de $3,5 \mathrm{~m}$ x $0,7 \mathrm{~m}$ e as de nogueira-macadâmia no espaçamento de $10,5 \mathrm{~m}$ x 4,9 $\mathrm{m}$, em coincidência com as fileiras de café (Figura 1). Considerando-se a importância da polinização cruzada sobre a produtividade da nogueira-macadâmia, as diferentes cultivares foram plantadas em faixas alternadas, com cada faixa composta de quatro fileiras de cada cultivar de nogueira-macadâmia. No consórcio, foram utilizadas 130 plantas de cada cultivar de macadâmia e 2.800 plantas de café, na área total. Também, plantou-se uma área com café solteiro, utilizando-se 1.000 mudas da cultivar Obatã (IAC 1669-20), no espaçamento de 3,5 m x 0,7 m. Assim, a área ocupada com o consórcio de café com cada uma das cultivares de nogueira-macadâmia, bem como com o café solteiro, foi de, aproximadamente, 0,23 ha.

As adubações foram feitas separadamente, com as plantas de nogueira-macadâmia adubadas conforme Barbosa et al. (1996) e as de café conforme Raij et al. (1996), sendo aplicados $250 \mathrm{~kg} \mathrm{ha}^{-1} \mathrm{ano}^{-1}$ da formulação $\mathrm{N}-\mathrm{P}_{2} \mathrm{O}_{5}-\mathrm{K}_{2} \mathrm{O}(20-05-20)$, na nogueira-macadâmia, e $1.500 \mathrm{~kg} \mathrm{ha}^{-1} \mathrm{ano}^{-1}$ da mesma formulação para o café, em média, nos anos de produção.
Tabela 1. Altura e diâmetro de copa de cultivares de nogueiramacadâmia consorciadas com café arábica irrigado, por ocasião da avaliação das plantas daninhas (Dois Córregos, SP, 2012).

\begin{tabular}{lcc}
\hline \multirow{2}{*}{ Cultivar } & Altura & \multicolumn{2}{c}{ Diâmetro de copa } \\
\cline { 2 - 3 } & \multicolumn{2}{c}{$\mathrm{m}$} \\
\hline HAES 816 & 5,4 & 4,0 \\
IAC 4-20 & 4,6 & 4,3 \\
IAC 9-20 & 5,4 & 4,9 \\
\hline
\end{tabular}

O levantamento de plantas daninhas foi realizado em março de 2012, aproximadamente seis anos após o plantio das culturas. Como unidade amostral, utilizou-se um quadro $(0,5 \mathrm{~m} \mathrm{x} 0,5 \mathrm{~m})$, segundo metodologia descrita por Gomes et al. (2010). Para cada local de amostragem das plantas daninhas (projeção da copa da nogueira-macadâmia, entre as copas da nogueira-macadâmia e na entrelinha do café arábica solteiro) (Figura 1), o quadrado foi lançado oito vezes.

Em cada quadro amostrado, as plantas foram identificadas e foi feita a determinação do número total de plantas daninhas, matéria seca da parte aérea e percentagem de controle, assim como a identificação das mesmas. O material coletado foi seco em estufa de circulação forçada de ar, a $60^{\circ} \mathrm{C}$, por 72 horas, sendo pesado, em seguida, e os dados transformados em $\mathrm{kg} \mathrm{ha}^{-1}$. Quanto à percentagem de controle, levou-se em consideração a redução no número de
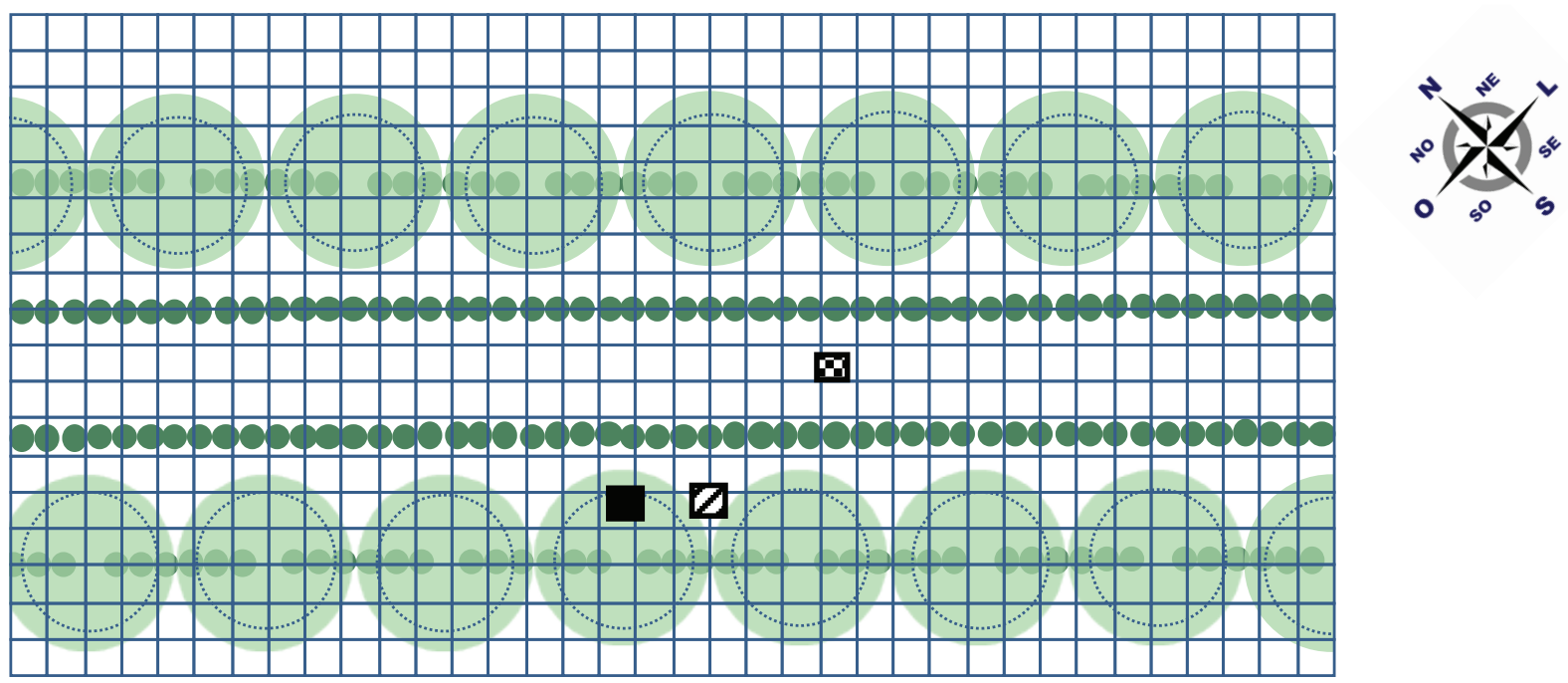

Figura 1. Representação esquemática do consórcio de café arábica (círculos menores) com nogueira-macadâmia (círculos maiores) e indicação dos locais de amostragem das plantas daninhas no consórcio: na projeção da copa ( $\square$ ), entre as projeções das copas $(\boldsymbol{Z})$ e na entrelinha solteira de café $(\boldsymbol{B})$ (Dois Córregos, SP, 2012). 
plantas daninhas por hectare, comparativamente ao café solteiro, que recebeu o valor de $0 \%$ de controle.

Para a caracterização fitossociológica, as plantas daninhas foram identificadas segundo a família, gênero e espécie, sendo, também, determinado o número de cada espécie presente em cada ponto de amostragem. Em função dos dados obtidos, foram estimadas as seguintes variáveis: densidade (D), abundância (A) e frequência (F). Destas, foram calculadas as variáveis frequência relativa $(\mathrm{Fr})$, densidade relativa (Dr) e abundância relativa (Ar), além do índice de valor de importância (IVI), seguindo-se metodologia empregada por Mueller-Dombois \& Ellenberg (1974) e Gomes et al. (2010), que utilizaram as seguintes fórmulas: $\mathrm{F}=\mathrm{n}^{\mathrm{o}}$ de quadrados que contêm a espécie $\div \mathrm{n}^{\mathrm{o}}$ total de quadrados obtidos (área total); $\mathrm{D}=\mathrm{n}^{\mathrm{o}}$ total de indivíduos por espécie $\div$ $\mathrm{n}^{\mathrm{o}}$ total de quadrados obtidos (área total); $\mathrm{A}=\mathrm{n}^{\mathrm{o}}$ total de indivíduos por espécie $\div \mathrm{n}^{\circ}$ total de quadrados que contêm a espécie; $\mathrm{Fr}=100 \mathrm{x}$ frequência da espécie : frequência total de todas as espécies; $\mathrm{Dr}=100 \mathrm{x}$ densidade da espécie $\div$ densidade total de todas as espécies; $\mathrm{Ar}=100 \mathrm{x}$ abundância da espécie $\div$ abundância total de todas as espécies; IVI $=\mathrm{Fr}+\mathrm{Dr}+\mathrm{Ar}$. Além disto, foi calculada a importância relativa $(\mathrm{Ir})=$ 100 x IVI da espécie $\div$ IVI total de todas as espécies (Gomes et al. 2010).

$\mathrm{Na}$ avaliação da similaridade (estimativa do grau de semelhança na composição de espécies) entre as populações botânicas, foi utilizado o índice de similaridade (IS), descrito em Odum (1985), por meio da fórmula IS $=(2 \mathrm{a} / \mathrm{b}+\mathrm{c}) \times 100$, em que "a" = número de espécies comuns nas duas áreas; "b" e "c" = número total de espécies nas duas áreas comparadas. O IS varia de 0 a 100, sendo máximo quando todas as espécies são comuns às duas áreas e mínimo quando não existem espécies em comum.

Para a análise dos dados de população, matéria seca da parte aérea e percentagem de controle de plantas daninhas, considerou-se delineamento inteiramente casualizado, em esquema fatorial $3 \times 3+1$, com oito repetições. Os tratamentos foram compostos pela combinação do café consorciado com três cultivares de nogueira-macadâmia (HAES 816, IAC 9-20 e IAC 4-20) e três locais de amostragem no consórcio (na projeção da copa da nogueira-macadâmia, entre as projeções das copas de nogueira-macadâmia e na entrelinha solteira, ou seja, aquela entre as fileiras que continham apenas plantas de café) (Figura 1), além de um tratamento adicional (café solteiro).
Os resultados para número de indivíduos, matéria seca da parte aérea e percentagem de controle das plantas daninhas foram submetidos à análise de variância, pelo teste $\mathrm{F}$. As médias dos tratamentos componentes do fatorial foram comparadas entre si pelo teste Tukey $(\mathrm{p} \leq 0,05)$. Os contrastes ortogonais dos tratamentos do fatorial foram comparados com o tratamento adicional (café solteiro), por meio do teste de Dunnett $(\mathrm{p} \leq 0,05)$.

\section{RESULTADOS E DISCUSSÃO}

A cultivar de nogueira-macadâmia IAC 9-20 apresentava, na época da avaliação, diâmetro de copa de 4,9 m (Tabela 1), ou seja, os ramos laterais das plantas vizinhas já haviam se encontrado, formado um renque contínuo na linha de plantio e tomado grande parte nas entrelinhas adjacentes, reduzindo a incidência de luz no solo, em grande parte do dia. Pezzopane et al. (2010) mediram a incidência de radiação fotossinteticamente ativa (RFA) no interior de cafezais arborizados por nogueira-macadâmia e concluíram que a presença de renques modificou o microclima no interior da lavoura e diminuiu a incidência da RFA em até $83 \%$ da RFA a pleno sol.

As espécies de plantas daninhas identificadas nas entrelinhas do consórcio de café arábica e nogueira-macadâmia, bem como na área de café solteiro, estão descritas na Tabela 2, com suas respectivas famílias, nomes científicos, nomes vulgares e códigos internacionais (Kissmann \& Groth 2000). Foram identificadas dezessete espécies, distribuídas em cinco famílias, destacando-se a família Poaceae, com oito espécies, a família Asteraceae, com quatro espécies, e a família Malvacea, com três espécies. As famílias Amaranthaceae e Rubiaceae apresentaram apenas uma única espécie identificada.

A densidade de plantas daninhas na projeção da copa não foi influenciada pelas cultivares de nogueira-macadâmia utilizadas (Tabela 3). Contudo, na posição de amostragem entre as plantas de nogueira-macadâmia, a cultivar IAC 9-20 permitiu menor população de plantas daninhas do que a cultivar HAES 816, porém, sem diferir da cultivar IAC 4-20. Isto foi possível devido ao fato de a cultivar IAC 9-20 apresentar copa com maior diâmetro (Tabela 1), o que, provavelmente, reduziu a incidência de luz entre as plantas, inibindo a emergência e o estabelecimento de plantas daninhas. Segundo Coelho et al. (2004), na cultura de café conilon consorciado com banana 
Tabela 2. Identificação de plantas daninhas em cultivo de café solteiro e consorciado com nogueira-macadâmia (Dois Córregos, SP, 2012).

\begin{tabular}{|c|c|c|c|c|c|}
\hline Família & Espécie & Nome vulgar & Código internacional & Tipo de folha & Ciclo \\
\hline Amaranthaceae & Amaranthus deflexus & Caruru & AMADE & FL & Anual \\
\hline Asteraceae & Bidens pilosa & Carrapicho-picão & BIDPI & FL & Anual \\
\hline Asteraceae & Conyza canadensis & Buva & ERICA & FL & Anual/bianual \\
\hline Asteraceae & Emilia sonchifolia & Serralha & EMISO & FL & Anual \\
\hline Asteraceae & Galinsoga parviflora & Botão-de-ouro & GASPA & FL & Anual \\
\hline Malvaceae & Anoda cristata & Malva-de-crista & ANVCR & FL & Anual \\
\hline Malvaceae & Sida cordifolia & Malva-branca & SIDCO & FL & Perene \\
\hline Malvaceae & Sida rhombifolia & Guanxuma & SIDRH & FL & Perene \\
\hline Poaceae & Brachiaria decumbens & Braquiária & BRADC & $\mathrm{FE}$ & Perene \\
\hline Poaceae & Brachiaria mutica & Capim-angola & PANPU & $\mathrm{FE}$ & Perene \\
\hline Poaceae & Brachiaria plantaginea & Capim-marmelada & BRAPL & FE & Anual \\
\hline Poaceae & Cenchrus echinatus & Carrapicho & CCHEC & $\mathrm{FE}$ & Anual \\
\hline Poaceae & Cynodon dactylon & Grama-seda & CYNDA & $\mathrm{FE}$ & Perene \\
\hline Poaceae & Digitaria insularis & Capim-amargoso & TRCIN & $\mathrm{FE}$ & Anual \\
\hline Poaceae & Digitaria horizontalis & Capim-colchão-miúdo & DIGHO & $\mathrm{FE}$ & Anual \\
\hline Poaceae & Digitaria sanguinalis & Capim-colchão & DIGSA & FE & Anual \\
\hline Rubiaceae & Spermacoce latifolia & Cordão-de-frade-branco & BOILF & FL & Anual \\
\hline
\end{tabular}

FE: folha estreita; FL: folha larga.

Tabela 3. Densidade, matéria seca da parte aérea e controle de plantas daninhas, em cultivo de café solteiro e consorciado com nogueira-macadâmia, em função do local de amostragem (Dois Córregos, SP, 2012).

\begin{tabular}{|c|c|c|c|c|}
\hline \multirow{2}{*}{ Cultivar de macadâmia } & \multicolumn{3}{|c|}{ Local de amostragem no consórcio } & \multirow{2}{*}{ Média } \\
\hline & Projeção da copa & Entre as copas & Entrelinha solteira & \\
\hline & & População (1 & $m^{-2}$ & \\
\hline HAES 816 & $2,4 \mathrm{aB}^{*}$ & $4,1 \mathrm{aB}^{*}$ & $7,8 \mathrm{bA}^{*}$ & 4,8 \\
\hline IAC $4-20$ & $2,0 \mathrm{aB}^{*}$ & $2,3 \mathrm{abB} *$ & $12,5 \mathrm{aA}$ & 5,6 \\
\hline IAC 9-20 & $1,5 \mathrm{aB}^{*}$ & $1,1 \mathrm{bB} *$ & $5,4 \mathrm{bA}^{*}$ & 2,7 \\
\hline Média & 2,0 & 2,5 & 8,5 & \\
\hline Café solteiro $=12,9$ & & & & \\
\hline \multicolumn{5}{|l|}{$\mathrm{CV}(\%)=28,5$} \\
\hline & & atéria seca da pc & $\left(k g h a^{-1}\right)$ & \\
\hline HAES 816 & $61,1 \mathrm{aB} *$ & $130,7 \mathrm{aB}^{*}$ & $473,6 \mathrm{aA}^{*}$ & 221,8 \\
\hline IAC $4-20$ & $28,2 \mathrm{aB}^{*}$ & $67,7 \mathrm{abB} *$ & $556,6 \mathrm{aA}^{*}$ & 217,5 \\
\hline IAC 9-20 & $32,1 \mathrm{aB} *$ & $17,7 \mathrm{bB}^{*}$ & $147,2 \mathrm{bA}^{*}$ & 65,7 \\
\hline Média & 40,5 & 72,0 & 392,4 & \\
\hline Café solteiro $=711,4$ & \multicolumn{4}{|c|}{$d^{\prime}=129,7$} \\
\hline \multicolumn{5}{|l|}{$\mathrm{CV}(\%)=32,2$} \\
\hline & & Con & & \\
\hline HAES 816 & $82 \mathrm{aA}^{*}$ & $68 \mathrm{bA}^{*}$ & $41 \mathrm{aB}^{*}$ & 63 \\
\hline IAC $4-20$ & $83 \mathrm{aA}^{*}$ & $81 \mathrm{abA} *$ & $9 \mathrm{bB}$ & 58 \\
\hline IAC 9-20 & $87 \mathrm{aA}^{*}$ & $90 \mathrm{aA}^{*}$ & $57 \mathrm{aB}^{*}$ & 78 \\
\hline Média & 84 & 80 & 36 & \\
\hline Café solteiro $=0$ & \multicolumn{4}{|c|}{$d^{\prime}=20,8$} \\
\hline $\mathrm{CV}(\%)=23,9$ & & & & \\
\hline
\end{tabular}

Médias seguidas de letras distintas, minúsculas na coluna e maiúsculas na linha, dentro de cada variável, diferem entre si, pelo teste Tukey (p = 0,05). d': diferença mínima significativa de Dunnett; * Diferença entre o valor médio e o tratamento "café solteiro", significativo pelo teste de Dunnett ( $\mathrm{p}=0,05)$.

e gliricídia, o sombreamento nas entrelinhas foi $86 \%$ maior que no café conilon consorciado apenas com banana, e isto reduziu em $96 \%$ a população de plantas daninhas.

Considerando-se os sistemas consorciados na entrelinha solteira (Figura 1), a maior população de plantas daninhas foi observada no consórcio com a cultivar IAC 4-20 (Tabela 3). Isto se deu devido ao fato de esta cultivar apresentar copa de diâmetro intermediário, mas com menor altura (Tabela 1), o que, provavelmente, levou a menor sombreamento da entrelinha de café solteiro, no consórcio. 
Ao avaliar a população de plantas daninhas, nos diferentes locais de amostragem utilizados no consórcio, observou-se maior população de plantas daninhas na entrelinha solteira, ou seja, entre duas fileiras que só continham plantas de café (Figura 1 e Tabela 3). Apenas na entrelinha solteira, no consórcio com a cultivar de nogueira-macadâmia IAC 4-20, a população de plantas daninhas não foi significativamente menor que na área de café solteiro. A maior população de plantas daninhas na área de café solteiro e na entrelinha solteira do consórcio de café com a cultivar de macadâmia de menor porte (IAC 4-20) ocorreu em virtude da maior área descoberta, favorecendo o desenvolvimento destas plantas. Silva et al. (2006) também observaram maior densidade de plantas daninhas em cafezal solteiro, quando comparado a cafezais com grevíleas.

Independentemente do local de amostragem, no consórcio houve menor produção de matéria seca da parte aérea de plantas daninhas do que na área de café solteiro (Tabela 3). Dentro do sistema de consórcio, não houve influência da projeção da copa da cultivar de nogueira-macadâmia sobre a matéria seca da parte aérea das plantas daninhas, porém, tanto na posição de amostragem entre as copas das plantas de nogueira-macadâmia como na entrelinha solteira, a cultivar IAC 9-20 proporcionou menores valores de matéria seca da parte aérea das plantas daninhas (Tabela 3).

De maneira geral, o consórcio com qualquer uma das cultivares de nogueira-macadâmia reduziu a matéria seca da parte aérea das plantas daninhas na projeção da copa e entre as plantas, em comparação com a entrelinha solteira. Silva et al. (2006) também verificaram que a consorciação de café arábica com plantas de grevílea reduziu a matéria seca de plantas daninhas na área, especialmente quando a densidade de plantas de grevílea foi maior. Coelho et al. (2004) verificaram que a arborização com plantas de glicirídia também reduziu a matéria seca de plantas daninhas, no consórcio de café conilon com banana.

O consórcio de café com nogueira-macadâmia proporcionou, em média, $84 \%$ de controle de plantas daninhas, na projeção da copa. Entre as projeções das copas das plantas da nogueira-macadâmia, o consórcio com a cultivar IAC 9-20 proporcionou controle de 90\%, superando a cultivar HAES 816, com controle de $68 \%$. Contudo, na entrelinha solteira, apenas as cultivares de nogueira-macadâmia mais altas (HAES 816 e IAC 9-20) proporcionaram controle significativo (49\%, em média), em comparação com o café solteiro (Tabela 3 ).
A cultivar de nogueira-macadâmia IAC 4-20, com média de 4,6 $\mathrm{m}$ de altura, praticamente não reduziu a incidência de plantas daninhas na entrelinha solteira do consórcio, em comparação com o café solteiro (Tabela 3). O uso de uma cultivar de nogueira-macadâmia de menor altura e de copa com diâmetro intermediário, como a IAC 4-20 (Tabela 1), proporcionou controle de $58 \%$ das plantas daninhas, no consórcio com café arábica, enquanto a cultivar IAC 9-20, com copa de maior altura e diâmetro, reduziu, em $78 \%$, a ocorrência de plantas daninhas, quando comparada com o café solteiro. Estes resultados indicam que o consórcio de café arábica com cultivares de nogueira-macadâmia influenciou, consideravelmente, na necessidade de controle químico ou mecânico de plantas daninhas, o que pode reduzir o custo de produção e os efeitos negativos das práticas de controle, nos atributos químicos, físicos e biológicos do solo (Alcântara \& Ferreira 2009, Alcântara et al. 2009, Araújo-Júnior et al. 2011, Pais et al. 2011).

$\mathrm{Na}$ análise fitossociológica das plantas daninhas, constatou-se que, na área de café solteiro, houve maior diversidade de espécies que no consórcio com nogueira-macadâmia, independentemente do local de amostragem (Tabela 4). Na área de café solteiro, foram observadas oito espécies monocotiledôneas e sete dicotiledôneas.

$\mathrm{Na}$ entrelinha solteira do consórcio, ou seja, aquela entre as fileiras que tinham apenas plantas de café (Figura 1), também houve maior diversidade de plantas daninhas que na projeção da copa e entre as projeções das copas de nogueira-macadâmia (Tabela 4). Nas entrelinhas adjacentes à fileira consorciada, tanto na projeção da copa como entre as projeções das copas das plantas de nogueira-macadâmia, o número de espécies de plantas daninhas foi menor que na área de café solteiro e na entrelinha solteira do consórcio.

$\mathrm{Na}$ área de café solteiro, a espécie de maior incidência foi a Cynodon dactylon, tendo sido contabilizados 63 indivíduos, nos oito quadros analisados, com densidade de 7,9 plantas $\mathrm{m}^{-2}$, frequência relativa (Fr) de $22,8 \%$ e importância relativa (Ir) de 39\% (Tabela 4). As espécies Digitaria horizontalis, D. sanguinalis e Spermacoce latilolia também apresentaram Ir igual ou superior a 10\%, na área de café solteiro. Assim, estas quatro espécies ( $C$. dactylon, $D$. horizontalis, D. sanguinalis e $S$. latilolia) representaram mais de $80 \%$ das plantas daninhas, na área de café solteiro. 
Tabela 4. Análise fitossociológica da comunidade de plantas daninhas identificadas na área de café solteiro e em cada local de amostragem no consórcio com cultivares de nogueira-macadâmia (Dois Córregos, SP, 2012).

\begin{tabular}{|c|c|c|c|c|c|c|}
\hline \multirow{2}{*}{ Tratamento } & \multirow{2}{*}{ Espécie } & \multirow{2}{*}{$\begin{array}{c}\mathrm{N}^{\mathrm{o}} \text { de } \\
\text { indivíduos }\end{array}$} & \multirow{2}{*}{$\begin{array}{c}\mathrm{N}^{0} \text { de quadros } \\
\text { ocupados }\end{array}$} & $\mathrm{D}$ & Fr & $\mathrm{Ir}$ \\
\hline & & & & $\mathrm{pl} \mathrm{m^{-2 }}$ & \multicolumn{2}{|c|}{ 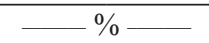 } \\
\hline \multirow{16}{*}{ Café solteiro } & Cynodon dactylon & 63 & 8 & 7,9 & 22,8 & 39,0 \\
\hline & Digitaria horizontalis & 11 & 3 & 1,4 & 8,6 & 11,6 \\
\hline & Digitaria sanguinalis & 10 & 3 & 1,3 & 8,6 & 11,1 \\
\hline & Spermacoce latifoia & 9 & 5 & 1,1 & 14,3 & 10,0 \\
\hline & Brachiaria mutica & 3 & 2 & 0,3 & 8,6 & 4,7 \\
\hline & Conyza canadensis & 3 & 2 & 0,3 & 5,7 & 4,6 \\
\hline & Amaranthus deflexus & 1 & 1 & 0,2 & 2,9 & 3,3 \\
\hline & Sida rhombifolia & 1 & 1 & 0,1 & 5,7 & 2,9 \\
\hline & Bidens pilosa & 1 & 1 & 0,1 & 5,7 & 2,9 \\
\hline & Emilia sonchifolia & 1 & 1 & 0,1 & 2,9 & 2,1 \\
\hline & Digitaria insularis & 1 & 1 & 0,1 & 2,9 & 1,5 \\
\hline & Sida cordifolia & 1 & 1 & 0,1 & 2,9 & 1,5 \\
\hline & Brachiaria plantaginea & 1 & 1 & 0,1 & 2,9 & 1,5 \\
\hline & Brachiaria decumbens & 1 & 1 & 0,1 & 2,9 & 1,5 \\
\hline & Cenhrus echinatus & 1 & 1 & 0,1 & 2,9 & 1,5 \\
\hline & Total & 104 & 35 & 12,9 & 100,0 & 100,0 \\
\hline \multirow{6}{*}{ HAES 816 - projeção da copa } & Cynodon dactylon & 7 & 4 & 0,9 & 33,3 & 31,7 \\
\hline & Spermacoce latifolia & 7 & 4 & 0,9 & 33,3 & 31,7 \\
\hline & Digitaria sanguinalis & 3 & 2 & 0,4 & 16,7 & 18,0 \\
\hline & Cenhrus echnatus & 1 & 1 & 0,1 & 8,3 & 9,3 \\
\hline & Galinsoga parviflora & 1 & 1 & 0,1 & 8,3 & 9,3 \\
\hline & Total & 19 & 12 & 2,4 & 100,0 & 100,0 \\
\hline \multirow{7}{*}{ HAES 816 - entre as copas } & Spermacoce latifoia & 15 & 7 & 1,9 & 43,8 & 37,7 \\
\hline & Cynodon dactylon & 14 & 5 & 1,8 & 31,3 & 35,0 \\
\hline & Digitaria sanguinalis & 1 & 1 & 0,1 & 6,3 & 6,8 \\
\hline & Sida rhombifolia & 1 & 1 & 0,1 & 6,3 & 6,8 \\
\hline & Sida cordifolia & 1 & 1 & 0,1 & 6,3 & 6,8 \\
\hline & Amaranthus deflexus & 1 & 1 & 0,1 & 6,3 & 6,8 \\
\hline & Total & 33 & 16 & 4,1 & 100,0 & 100,0 \\
\hline & Spermacoce latifolia & 23 & 5 & 2,9 & 23,8 & 27,0 \\
\hline & Cynodon dactylon & 9 & 3 & 1,1 & 14,3 & 13,9 \\
\hline & Digitaria sanguinalis & 8 & 3 & 1 & 14,3 & 12,9 \\
\hline & Conyza canadensis & 6 & 2 & 0,8 & 9,5 & 10,6 \\
\hline & Digitaria horizontalis & 4 & 1 & 0,5 & 4,8 & 9,3 \\
\hline HAES 816 - entrelinha solteira & Sida rhombifolia & 3 & 2 & 0,4 & 9,5 & 6,9 \\
\hline & Bidens pilosa & 3 & 2 & 0,4 & 9,5 & 6,9 \\
\hline & Emilia sonchifolia & 2 & 1 & 0,3 & 4,8 & 5,4 \\
\hline & Digitaria insularis & 1 & 1 & 0,1 & 4,8 & 3,5 \\
\hline & Sida cordifolia & 1 & 1 & 0,1 & 4,8 & 3,5 \\
\hline & Total & 60 & 21 & 7,5 & 100,0 & 100,0 \\
\hline & Cynodon dactylon & 7 & 5 & 0,9 & 35,7 & 30,9 \\
\hline & Spermacoce latifoia & 6 & 4 & 0,8 & 28,6 & 27,3 \\
\hline IAC 4-20 - projeção da copa & Digitaria sanguinalis & 3 & 3 & 0,4 & 21,4 & 17,2 \\
\hline & Anoda cristata & 2 & 1 & 0,3 & 7,1 & 15,6 \\
\hline & Digitaria horizontalis & 1 & 1 & 0,1 & 7,1 & 9,0 \\
\hline & Total & 19 & 14 & 2,4 & 100,0 & 100,0 \\
\hline & Cynodon dactylon & 12 & 6 & 1,5 & 54,5 & 52,9 \\
\hline & Spermacoce latifoia & 4 & 3 & 0,5 & 27,3 & 24,8 \\
\hline IAC 4-20 - entre as copas & Digitaria sanguinalis & 1 & 1 & 0,1 & 9,1 & 11,1 \\
\hline & Amaranthus deflexus & 1 & 1 & 0,1 & 9,1 & 11,1 \\
\hline & Total & 18 & 11 & 2,3 & 100,0 & 100,0 \\
\hline & Cynodon dactylon & 55 & 8 & 6,9 & 38,1 & 38,5 \\
\hline & Digitaria horizontalis & 15 & 3 & 1,9 & 14,3 & 15,0 \\
\hline & Digitaria sanguinalis & 12 & 2 & 1,5 & 9,5 & 13,4 \\
\hline & Spermacoce latifoia & 4 & 1 & 0,5 & 4,8 & 7,1 \\
\hline & Amaranthus deflexus & 4 & 1 & 0,5 & 4,8 & 7,1 \\
\hline IAC 4-20 - entrelinha solteira & Conyza canadensis & 3 & 2 & 0,4 & 9,5 & 5,7 \\
\hline & Brachiaria mutica & 2 & 1 & 0,3 & 4,8 & 4,3 \\
\hline & Brachiaria plantaginea & 1 & 1 & 0,1 & 4,8 & 3,0 \\
\hline & Brachiaria decumbens & 1 & 1 & 0,1 & 4,8 & 3,0 \\
\hline & Cenhrus echnatus & 1 & 1 & 0,1 & 4,8 & 3,0 \\
\hline & Total & 98 & 21 & 12,3 & 100,0 & 100,0 \\
\hline & Cynodon dactylon & 5 & 4 & 0,6 & 66,7 & 41,2 \\
\hline & Digitaria horizontalis & 4 & 1 & 0,5 & 16,7 & 32,8 \\
\hline IAC 9-20 - projeçao da copa & Digitaria sanguinalis & 3 & 1 & 0,4 & 16,7 & 26,0 \\
\hline & Total & 12 & 6 & 1,5 & 100,0 & 100,0 \\
\hline & Cynodon dactylon & 6 & 5 & 0,8 & 100,0 & 100,0 \\
\hline IAC 9-20 - entre as copas & Total & 6 & 5 & 0,8 & 100,0 & 100,0 \\
\hline & Cynodon dactylon & 20 & 6 & 2,5 & 40,0 & 40,3 \\
\hline & Digitaria horizontalis & 10 & 3 & 1,3 & 20,0 & 25,5 \\
\hline IAC 9-20 - entrelinha solteira & Digitaria sanguinalis & 6 & 3 & 0,8 & 20,0 & 18,0 \\
\hline & Brachiaria mutica & 5 & 3 & 0,6 & 20,0 & 16,1 \\
\hline & Total & 41 & 15 & 5,1 & 100,0 & 100,0 \\
\hline
\end{tabular}

D: densidade; Fr: frequência relativa; Ir: importância relativa. 
Tabela 5. Índice de similaridade das comunidades de plantas daninhas ocorrentes em áreas de café solteiro e de consórcio com cultivares de nogueira-macadâmia, em resposta à consorciação, à cultivar de nogueira-macadâmia utilizada e ao local de amostragem no consórcio (Dois Córregos, SP, 2012).

\begin{tabular}{llc}
\hline \multicolumn{1}{c}{ Critério de comparação } & \multicolumn{1}{c}{ Comparação } & IS (\%) \\
\hline \multirow{3}{*}{ Consorciação } & Café solteiro x consórcio com HAES 816 & 85,7 \\
& Café solteiro x consórcio com IAC 4-20 & 76,9 \\
& Café solteiro x consórcio com IAC 9-20 & 42,1 \\
\hline \multirow{3}{*}{ Cultivar de nogueira-macadâmia } & HAES 816 x IAC 4-20 & 58,3 \\
& HAES 816 x IAC 9-20 & 35,3 \\
& IAC 4-20 x IAC 9-20 & 53,3 \\
\hline \multirow{2}{*}{ Local de amostragem } & Projeção da copa x entre as copas & 50,0 \\
& Projeção da copa x entrelinha solteira & 36,4 \\
& Entre as copas x entrelinha solteira & 50,0 \\
\hline
\end{tabular}

A espécie C. dactylon também apresentou maior Ir, no consórcio do café com as cultivares de nogueira-macadâmia, com exceção das amostragens realizadas entre as copas e na entrelinha solteira da cultivar HAES 816, demonstrando que, mesmo sob relativo sombreamento, esta espécie se sobressaiu entre as demais (Tabela 4). Na amostragem entre as plantas e na entrelinha solteira da área de consórcio de café arábica com a nogueira-macadâmia HAES 816, a espécie dicotiledônea $S$. latifolia se destacou com maior Fr e Ir que a monocotiledônea $C$. dactylon. Silva et al. (2006) observaram menor diversidade e predominância de plantas daninhas monocotiledôneas, em cafezais a pleno sol, do que naqueles consorciados com grevíleas, no Estado da Bahia.

No consórcio de café arábica com a cultivar IAC 9-20, foi observada menor diversidade de plantas daninhas que no consórcio com as demais cultivares (Tabela 4). Isto, provavelmente, ocorreu devido à copa de maior altura e diâmetro desta cultivar (Tabela 1), a qual promoveu maior sombreamento. Coelho et al. (2004) também observaram menor diversidade de plantas daninhas em cafezais com maior nível de sombreamento, proporcionado pelo cultivo consorciado com glirícidia, no Estado do Rio de Janeiro.

O índice de similaridade (IS) indicou que existiu maior diferença de espécies entre o café solteiro e o consórcio de café com a nogueira-macadâmia cultivar IAC 9-20 (Tabela 5), provavelmente devido à copa mais larga desta cultivar, o que promoveu menor densidade de espécies (Tabela 4). Na comparação entre as cultivares de nogueira-macadâmia utilizadas no consórcio, verificou-se menor IS, na comparação entre a HAES 816 e a IAC 9-20. Já com relação ao local de amostragem, observou-se menor IS quando comparou-se a projeção da copa com a entrelinha sol- teira, indicando que o sombreamento proporcionado pelas copas da nogueira-macadâmia proporcionou ocorrência de um número de espécies bem inferior ao observado na entrelinha solteira (Tabelas 4 e 5). Segundo Carvalho \& Pitelli (1992), o IS está relacionado ao solo e à distância entre áreas, bem como às formas de manejo empregadas nestas áreas, que podem influenciar na germinação e desenvolvimento de plantas daninhas.

Diante do exposto, é possível que as condições edafoclimáticas da região e as práticas de manejo, bem como a espécie ou cultivar de árvore utilizada no consórcio, interfiram na diversidade de plantas daninhas que ocorrem na cultura do café. Cultivares de nogueira-macadâmia com copas mais altas e de maior diâmetro, como a IAC 9-20, proporcionaram menor ocorrência de plantas daninhas, no consórcio com café arábica, porém, deve-se considerar que, possivelmente, também podem ocasionar menor produtividade dos cafeeiros, no consórcio.

\section{CONCLUSÕES}

1. No cultivo de café consorciado com nogueira-macadâmia, seis anos após o plantio, a ocorrência e o número de espécies de plantas daninhas foram, em média, $33 \%$ menores que no cultivo de café solteiro.

2. Na projeção da copa e entre a projeção das copas da nogueira-macadâmia, houve, em média, $82 \%$ de redução na ocorrência de plantas daninhas, em comparação com o café solteiro.

3. A cultivar de nogueira-macadâmia IAC 9-20, por apresentar copa mais alta e de maior diâmetro, foi mais eficiente na redução da ocorrência de plantas daninhas, no consórcio com café arábica. 


\section{AGRADECIMENTOS}

À Fundação de Apoio à Pesquisa do Estado de São Paulo (FAPESP), pelo auxílio financeiro (Processo $n^{\circ}$ 2011/17940-0), e ao Conselho Nacional de Desenvolvimento Científico e Tecnológico (CNPq), pela concessão de bolsa de Produtividade em Pesquisa, ao terceiro autor.

\section{REFERÊNCIAS}

AGRIANUAL 2013: anuário da agricultura brasileira. São Paulo: Informa Economics FNP, 2012.

ALCÂNTARA, E. N.; FERREIRA, M. M. Efeito de métodos de controle de plantas daninhas na produção de café durante 30 anos. In: SIMPÓSIO DE PESQUISA DOS CAFÉS DO BRASIL, 6., 2009, Vitória. Anais... Brasília, DF: Embrapa Café, 2009. 1 CD-ROM.

ALCÂNTARA, E. N.; NÓBREGA, J. C. A.; FERREIRA, M. M. Métodos de controle de plantas daninhas no café afetam os atributos químicos do solo. Ciência Rural, Santa Maria, v. 39, n. 3, p. 749-757, 2009.

ARAÚJO-JÚNIOR, C. F. et al. Alterações nos atributos químicos de um Latossolo pelo manejo de plantas invasoras em cafeeiros. Revista Brasileira de Ciência do Solo, Viçosa, v. 35, n. 6, p. 2207-2217, 2011.

BARBOSA, W. et al. Frutas de clima temperado: III. Caqui, maçã, macadâmia, pecã e pêra. In: RAIJ, B. V. et al. (Eds.). Recomendações de adubação e calagem para o Estado de São Paulo. 2. ed. Campinas: Instituto Agronômico/ Fundação IAC, 1996. p. 141-142. (Boletim técnico, 100).

CAMARGO, M. B. P. The impact of climatic variability and climate change on Arabic coffee crop in Brazil. Bragantia, Campinas, v. 69, n. 1, p. 239-247, 2010.

CARVAlHO, L. B.; ALVES, P. L. C. A.; BIANCO, S. Sourgrass densities affecting the initial growth and macronutrient content of coffee plants. Planta Daninha, Viçosa, v. 31, n. 1, p. 109-115, 2013.

CARVALHO, S. L.; PITELLI, R. A. Comportamento e análise fitossociológica das principais espécies de plantas daninhas de pastagens da região de Selvíria, MS. Planta Daninha, Londrina, v. 10, n. 1/2, p. 25-32, 1992.

CENTRO DE PESQUISAS METEOROLÓGICAS E CLIMÁTICAS APLICADAS À AGRICULTURA (Cepagri). Clima dos municipios paulistas. 2012. Disponível em: <http://www.cpa.unicamp.br/outrasinforma\%C3\%A7\%C3\%B5es/clim_muni_279.html>. Acesso em: 10 abr. 2012.

COELHO, R. A. et al. Influência do sombreamento sobre a população de plantas espontâneas em área cultivada com cafeeiro (Coffea canephora) sob manejo orgânico. Agronomia, Seropédica, v. 38, n. 2, p. 23-28, 2004.
DAMATTA, F. M. et al. Ecophysiology of coffee growth and production. Brazilian Journal of Plant Physiology, Campos dos Goytacazes, v. 19, n. 4, p. 485-510, 2007.

FERREIRA, E. A. et al. Avaliação fitossociológica da comunidade infestante em área de transição para o café orgânico. Planta Daninha, Viçosa, v. 29, n. 3, p. 565-576, 2011.

FIALHO, C. M. T. et al. Competição de plantas daninhas com a cultura do café em duas épocas de infestação. Planta Daninha, Viçosa, v. 28, n. esp., p. 969-978, 2010.

GOMES, G. L. G. C. et al. Cadastramento fitossociológico de plantas daninhas na bananicultura. Planta Daninha, Viçosa, v. 28, n. 1, p. 61-68, 2010.

KISSMANN, K. G.; GROTH, D. Plantas infestantes e nocivas. 2. ed. São Paulo: BASF, 2000.

MUELLER-DOMBOIS, D.; ELLEMBERG, H. A. Aims and methods of vegetation ecology. New York: John Wiley, 1974.

ODUM, E. P. Ecologia. Rio de Janeiro: Interamericana, 1985.

PAIS, P. S. M. et al. Compactação causada pelo manejo de plantas invasoras em Latossolo Vermelho-Amarelo cultivado com cafeeiros. Revista Brasileira de Ciência do Solo, Viçosa, v. 35, n. 6, p. 1949-1957, 2011.

PERDONÁ, M. J. et al. Crescimento e produtividade de nogueira-macadâmia em consórcio com cafeeiro arábica irrigado. Pesquisa Agropecuária Brasileira, Brasília, DF, v. 47, n. 11, p. 1613-1620, 2012.

PEZZOPANE, J. R. M.; PEDRO JÚNIOR, M. J.; GALLO, P. B. Caracterização microclimática em cultivo consorciado café/banana. Revista Brasileira de Engenharia Agrícola e Ambiental, Campina Grande, v. 11, n. 3, p. 256-264, 2007.

PEZZOPANE, J. R. M. et al. Condições microclimáticas em cultivo de café conilon a pleno sol e arborizado com nogueira macadâmia. Ciência Rural, Santa Maria, v. 40, n. 6, p. 1257-1263, 2010.

RAIJ, B. V.; CANTARELla, H.; QUAGgIO, A. J. Estimulantes: café. In: RAIJ, B. V. et al. (Eds.). Recomendações de adubação e calagem para o Estado de São Paulo. 2. ed. Campinas: Instituto Agronômico/Fundação IAC, 1996. p. 97-101. (Boletim técnico, 100).

SANTOS, H. G. et al. (Eds.). Sistema brasileiro de classificação de solos. 2. ed. Rio de Janeiro: Embrapa Solos, 2006.

SCHULZ, B.; BECKER, B.; GÖTSCH, E. Indigenous knowledge in a 'modern' sustainable agroforestry system. Agroforestry Systems, Dordrecht, v. 25, n. 1, p. 59-69, 1994.

SILVA, S. O. et al. Diversidade e frequência de plantas daninhas em associação entre cafeeiros e grevíleas. Coffee Science, Lavras, v. 1, n. 2, p. 126-134, 2006. 